\title{
COMPARISON OF LATVIAN QUALIFIED BASKETBALL AND HANDBALL PLAYERS PERFORMANCE
}

\author{
Inese Pontaga \\ Department of Anatomy, Physiology, Biochemistry and Hygiene, Latvian Academy of Sports \\ Education, Riga, Latvia \\ Janis Zidens \\ Department of Sport Games, Latvian Academy of Sports Education, Riga, Latvia
}

\begin{abstract}
The aim of our investigation was to compare qualified basketball and handball players' anthropometric and performance (aerobic and anaerobic endurance, explosive power) characteristics. Male handball and basketball players from Premium league teams voluntary participated. The aerobic endurance was measured on a treadmill, the intensity of running increased step by step, the test was performed to exhaustion. The oxygen uptake, heart rate and running speed were measured. The lactate concentration was detected in periphery blood samples by special strips in the end of every load step and after the test. Maximal vertical jump heights of the counter-movement jump with hands on the hips and the free jump with motions of arms were measured on a special device. The height of basketball players is higher in comparison with handball players $(p=0.002)$, but the body weight and body mass index did not differed significantly $(p>0.05)$. The aerobic endurance characteristics (heart rate and oxygen uptake at the anaerobic threshold load intensity, and maximal oxygen uptake) were greater in basketball than in handball players $(p<0.04)$. The maximal lactate concentration in blood plasma two minutes after the test was higher in handball players than in basketball players $(p=0.043)$. The vertical jump heights are the same in basketball and handball players $(p>0.05)$.
\end{abstract}

Keywords: anthropometric characteristics, aerobic endurance, anaerobic endurance, jump height, basketball, team handball.

\section{Introduction}

Both sport games: basketball and team handball have an intermittent nature of movements and their intensity. Therefore players combine elements of power, anaerobic and aerobic endurance exercises during training.

The players experience, anthropometric characteristics, body composition, endurance, balance between anaerobic and aerobic power, are very important in evaluating elite basketball players (Hoffman, 2003; Ostojic, 2006). The First league basketball players are taller and had a higher maximal reach height, this results in higher jumping reach height and better game jumping performance of the First league players in comparison with the Second league players 
Pontaga \& Zidens, 2018. Comparison of Latvian Qualified Basketball and Handball Players Performance

(Pehar et al., 2017). The basketball players need high levels of muscles’ power to achieve fast running speed and powerful jumping. An aerobic capacity is important to maintain high performance level of the athletes throughout all the play match (Hoffman, 2003; Ostojic, 2006).

A large height and lean body mass due to hypertrophied skeletal muscles are beneficial for performance also in adult professional handball players because a taller stature is an advantage for throwing, stealing and handling of the ball in a direct duel with an opponent during the match play (Gorostiaga et al., 2005; Pontaga \& Zidens, 2011). Handball players need high levels of anaerobic capacities to achieve a fast running speed, powerful jumping and ball throwing because team handball is a very strenuous sport (Rannou et al., 2001; Ziv \& Lidor, 2009; Ingebrigtsen et al., 2013). The higher values of absolute muscles strength and power characteristics (including vertical jump height) in the professional handball players in comparison with amateur or lower level players indicate that these characteristics are important for successful performance in high-level handball (Gorostiaga et al., 2005; Pontaga \& Zidens, 2012; Nikolaidis \& Ingebrigtsen, 2013). The intensity of exercises during basketball game also is high: approximately $15 \%$ of the play-match time is spent in anaerobic exercises (McInnes et al., 1995). The great skeletal muscles mass may be beneficial for throwing power improvement, but may decrease jumping height of both: basketball and handball players.

Majority of the activity in the basketball game is performed at aerobic intensity (McInnes et al., 1995). An aerobic capacity also is important to maintain high performance level of the athletes throughout all duration of the handball game (Gorostiaga et al., 2005; Rannou et al., 2001). Buchheit M. et al. (2009) detected that close to $90 \%$ of the energy released during a handball game is supplied by aerobic mechanisms. An improved aerobic capacity must be important also for a faster recovery between high-intensity efforts during match play (Rannou et al., 2001), and a greater resistance to fatigue during training and competitions (Zapartidis et al., 2009). The fatigue is a reason of reduced throwing accuracy towards the end of each half in a simulated handball game (Zapartidis et al., 2007).

The knowledge about anthropometric and performance characteristics of high-level basketball and handball players could be used by coaches to make better selection of players and to design training programs according to the specific needs of each sport game player (Ostojic, 2006).

The aim of our investigation was to compare qualified basketball and handball players' anthropometric and performance (aerobic and anaerobic endurance, explosive power) characteristics. 


\section{Methods}

Thirty-four high-level male athletes who played in Latvian Premium league teams (20 basketball and 14 handball players) were informed of the possible risks of participation and voluntarily participated in the investigation. Their training experience in basketball or team handball ranged from seven to 14 years. These athletes trained five times per week (ten to 15 hours per week) and played regularly on the weekends. The study was performed in accordance with the standards of the local Ethics Committee and in accordance with the Declaration of Helsinki.

The athletes' height was measured using an Ultrasound Height Measuring Unit MZ10020 (ADE, Hamburg). Body mass was measured in basketball and handball players wearing briefs using a Body Composition Analyser BC-418 (Tanita Corporation, Japan), and the error of measurement was $0.1 \mathrm{~kg}$.

An aerobic endurance performance of the basketball and handball players was determined on a treadmill (Cosmos system performance diagnostics, Germany). The running speed increased step by step for every two minutes by $0.25 \mathrm{~m} / \mathrm{s}$. Every participant performed the test to exhaustion. A cardiopulmonary diagnostic equipment „Oxygen Mobile Via Sys” (Via Sys Healthcare GMBH, Germany) was used to register an electrocardiogram and respiratory characteristics. In our investigation we used the characteristics: heart rate HR (in beats per minute), relative volume of oxygen uptake $\mathrm{VO}_{2}$ (in litres per minute per body mass kilogram), and running speed on the treadmill (in meters per second). Mean values of all characteristics in the last minute of each load step were calculated. Gas analysers are calibrated before and after each test. A lactic acid concentration in the capillary blood was detected by a special lactate analysers „Biosen 5030” (EKG - diagnostic, Germany). The lactic acid concentration in the capillary blood was determined every two minutes (in the end of every load intensity step) and two minutes after finishing of the load test performed to exhaustion.

The average aerobic performance characteristics were determined at the anaerobic threshold (AnT) intensity workload (onset of the blood lactate accumulation), when the lactate concentration in the capillary blood rapidly increased (it was below or close to $4 \mathrm{mmol} / \mathrm{l}$ ). The break point was seen in relationship between the treadmill workload (running speed) and concentration of the lactate in the blood (Sjodin \& Jacobs, 1981). Rapid increase of the lactate concentration was observed, when the running speed exceeded the AnT level due to intensive anaerobic glycolysis in the muscles fibres in energy providing. The same aerobic performance characteristics were determined at the maximal oxygen uptake load. 
Pontaga \& Zidens, 2018. Comparison of Latvian Qualified Basketball and Handball Players Performance

A Personal Computer based diagnostic system FiTRO Jumper (Fitros, Bratislava, Slovakia) was used for assessment of jumping performance. The system (consisting of contact switch mats connected by means of an USB interface to the computer) measured contact and flight times (with accuracy of one millisecond) and calculated vertical jump height of serial jumps. Before the vertical jump test the athletes performed general warming up for eight to nine minutes: this included low - to moderate intensity jogging and jumping rope. After warming up exercises they performed five vertical jumps with squatting and holding the hands on the hips or counter-movement jumps (CMJ). After the rest with duration of six to eight minutes the participants performed the next five vertical jumps with squatting and free movement of the arms or free jumps (CMJA) on the diagnostic system FiTRO Jumper. The best repetition (the highest jump) from every kind of serial jumps (CMJ and CMJA) was taken into account. The maximal jump height (in centimetres) was estimated.

The anthropometric and performance characteristics data of basketball and handball players groups were normally distributed. Mean values and standard deviations (SD) for all characteristics were calculated. Student's $t$ - test for unequal data groups was employed to determine differences between the anthropometric and physiological characteristics at anaerobic threshold and maximal intensity loads, and vertical jump tests results in qualified basketball and handball players. The differences were considered to be statistically significant at $\mathrm{p}<0.05$. Microsoft Excel 2010 program and MS additional program "Statistics 5.01." (Dravnieks, 2017) were used to perform all statistical procedures.

\section{Results}

The mean age, body height, body mass and body mass index of the tested athletes are shown in the Table 1 . The mean height of basketball players was significantly higher in comparison with the height of handball players $(\mathrm{p}=0.002)$, the body mass and body mass index did not differ significantly in these two groups of players $(\mathrm{p}>0.05)$.

Table 1 Mean anthropometric characteristics $( \pm$ SD) of basketball and handball players from Premium league teams

\begin{tabular}{|l|c|c|c|c|}
\hline \multicolumn{1}{|c|}{ Participants } & $\begin{array}{c}\text { Mean age } \pm \\
\text { SD, years }\end{array}$ & $\begin{array}{c}\text { Mean height } \pm \\
\text { SD, cm }\end{array}$ & $\begin{array}{c}\text { Mean body mass } \\
\pm \text { SD, kg }\end{array}$ & $\begin{array}{c}\text { Mean body mass } \\
\text { index (BMI) } \pm \text { SD, } \\
\text { kg/m }\end{array}$ \\
\hline Basketball players & $21.4 \pm 1.0$ & $196.9 \pm 8.3$ & $90.7 \pm 13.0$ & $23.4 \pm 2.3$ \\
\hline Handball players & $20.6 \pm 0.9$ & $186.8^{*} \pm 8.1$ & $85.9 \pm 11.3$ & $24.2 \pm 1.8$ \\
\hline $\begin{array}{l}\text { Significance of } \\
\text { difference }\end{array}$ & $\begin{array}{c}\mathrm{p}=0.063 \\
\text { N.S. }\end{array}$ & $\mathrm{p}=0.002$ & $\mathrm{p}=0.165$ & $\mathrm{p}=0.249$ \\
$\mathrm{~N} . \mathrm{S}$. & \\
\hline
\end{tabular}

N.S. - none significant 
The mean relative oxygen uptake at the anaerobic threshold and maximal oxygen uptake load intensity were significantly greater in high-level male basketball players in comparison with high-level handball players $(p=0.01)$, Table 2. The mean heart rate at the anaerobic threshold load intensity was significantly higher in basketball players than in handball players $(p=0.039)$, but the mean running speed at this load intensity did not significantly differed in the players of both sport games ( $p>0.05)$. The difference between the mean maximal heart rate (measured at the maximal oxygen uptake load intensity) in both groups of participants was none significant ( $p>0.05)$.

The maximal lactate concentration in periphery blood taken two minutes after the load test on treadmill performed to exhaustion was significantly greater in qualified male handball players than in high-level basketball players ( $\mathrm{p}=$ 0.043), Table 2.

Table 2 Mean ( \pm SD) aerobic endurance characteristics at the anaerobic threshold and maximal intensity load, maximal lactate concentration in blood two minutes after the load test in qualified male basketball and handball players

\begin{tabular}{|c|c|c|c|c|c|c|}
\hline Load & \multicolumn{3}{|c|}{ Anaerobic threshold } & \multicolumn{3}{|c|}{ Maximal aerobic power } \\
\hline Participants & $\begin{array}{l}\mathrm{VO}_{2} \max \\
\mathrm{ml} / \mathrm{kg} \cdot \min \end{array}$ & $\begin{array}{l}\text { HR, } \\
\text { beats/ } \\
\text { min }\end{array}$ & $\begin{array}{l}\text { Running } \\
\text { speed, } \\
\mathrm{m} / \mathrm{s}\end{array}$ & $\begin{array}{l}\mathrm{VO}_{2}, \\
\mathrm{ml} / \mathrm{kg} \cdot \min \end{array}$ & $\begin{array}{l}\text { HR, beats/ } \\
\text { min }\end{array}$ & $\begin{array}{l}\text { Lactate } \\
\max , \\
\mathrm{mmol} / \mathrm{l}\end{array}$ \\
\hline $\begin{array}{l}\text { Basketball } \\
\text { players }\end{array}$ & $48.5 \pm 4.7$ & $174 \pm 6$ & $3.70 \pm 0.36$ & $54.2 \pm 5.9$ & $186 \pm 7$ & $\begin{array}{l}9.3 \pm \\
1.3\end{array}$ \\
\hline $\begin{array}{l}\text { Handball } \\
\text { players }\end{array}$ & $41.6^{*} \pm 4.9$ & $169 * \pm 6$ & $3.63 \pm 0.24$ & $46.5^{*} \pm 4.6$ & $185 \pm 6$ & $\begin{array}{l}10.8^{*} \pm \\
2.0\end{array}$ \\
\hline $\begin{array}{l}\text { Significance } \\
\text { of difference }\end{array}$ & $\mathrm{p}=0.001$ & $\mathrm{p}=0.039$ & $\begin{array}{c}\mathrm{p}=0.492 \\
\text { N.S. }\end{array}$ & $\mathrm{p}=0.001$ & $\begin{array}{c}\mathrm{p}=0.518 \\
\text { N.S. }\end{array}$ & $\mathrm{p}=0.043$ \\
\hline
\end{tabular}

N.S. - none significant

Table 3 Mean maximal height $( \pm$ SD) of counter-movement and free jump (countermovement jump with free motion of the arms) in high-level male basketball and handball players

\begin{tabular}{|l|c|c|}
\hline Participants & $\begin{array}{c}\text { Height of the counter- } \\
\text { movement jump, cm }\end{array}$ & Height free jump, cm \\
\hline Basketball players & $47.4 \pm 7.8$ & $57.8 \pm 9.0$ \\
\hline Handball players & $47.6 \pm 7.6$ & $57.1 \pm 10.1$ \\
\hline Significance of difference & $\mathrm{p}=0.954 ;$ N.S. & $\mathrm{p}=0.849 ;$ N.S. \\
\hline
\end{tabular}

N.S. - none significant 
Pontaga \& Zidens, 2018. Comparison of Latvian Qualified Basketball and Handball Players Performance

The mean maximal height of counter-movement and free jump did not differed significantly in qualified male basketball and handball players $(p>0.05)$, Table 3.

\section{Discussion}

Our high-level basketball players are taller for approximately $10 \mathrm{~cm}$ in comparison with the same level Latvian handball players (Table 1), but the mean body mass and the body mass index differ none significantly in these two groups of players. The mean anthropometric characteristics of Latvian basketball players from Premium league teams (mean height: $196.9 \pm 8.3 \mathrm{~cm}$; body mass: $90.7 \pm 13.0$ kg; age: $21.4 \pm 1.0$ years) are very close with professional basketball players from Bosnia and Herzegovina (mean height: $194.92 \pm 8.09 \mathrm{~cm}$; body mass: 89.33 \pm 10.91 kg; age: 21.58 \pm 3.92 years) determined by Pehar et al. (2017).

The mean stature of the professional handball players from Spain: $188.7 \pm$ $8.0 \mathrm{~cm}$ (Gorostiaga et al., 2005) and France: $190.0 \pm 1.2 \mathrm{~cm}$ (Rannou et al., 2001) slightly exceeds the mean height of Latvian Premium league players (186.8 \pm 8.1 $\mathrm{cm})$, but the stature of the First league best team players from Greece (185.1 \pm 6.5 $\mathrm{cm}$ ) is similar like in Latvian players (Nikolaidis \& Ingebrigtsen, 2013). The professional players from Spain with the mean body mass $95 \pm 13 \mathrm{~kg}$ (Gorostiaga et al., 2005) are heaver for approximately $10 \mathrm{~kg}$ than our players (the mean body mass: $85.9 \pm 11.3 \mathrm{~kg}$ ). This can be explained by greater skeletal muscles mass in the professional level Spanish athletes: their fat free body mass is $81.7 \pm 9 \mathrm{~kg}$, but body fat is in norm: $13.8 \pm 2 \%$ (Gorostiaga et al., 2005) in comparison with our players. From our previous data (Pontaga \& Zidens, 2011) the fat free body mass in Latvian young handball players (age $17.6 \pm 1.0$ years) from Murjani Sport Gymnasium (Premium league team) is $73.9 \pm 5.2 \mathrm{~kg}$ and body fat is in norm: 13.6 $\pm 2.8 \%$, but the mean body mass index is greater in this team players $(25.1 \pm 2.9$ $\left.\mathrm{kg} / \mathrm{m}^{2}\right)$ in comparison with this characteristic in the present team $(24.2 \pm 1.8$ $\mathrm{kg} / \mathrm{m}^{2}$ ). Our handball players are heaver in comparison with the professional (mean body mass $79 \pm 1 \mathrm{~kg}$ ) players from France (Rannou et al., 2001). The body mass of the First league best team handball players from Greece (87.6 $\pm 9.0 \mathrm{~kg})$ is close to the mass $(85.9 \pm 11.3 \mathrm{~kg})$ of Latvian players (Nikolaidis \& Ingebrigtsen, 2013).

The vertical jumping height is especially important for basketball players because the game is oriented around a basket that is set at a top height of $3.05 \mathrm{~m}$. Therefore taller players are able to outperform their opponents in numerous situations requiring offensive and defensive responsibilities: blocking, jump shooting, rebounding (Miura et al., 2010; Struzik et al., 2014). The vertical jump maximal height is similar across different playing levels and positions of basketball players (First league vs. Second league or guards, forward and centre 
players), but differences in the anthropometrics between the players competing at the two levels are evident: First league players were taller and had a higher maximal reach height (Pehar et al., 2017). This higher stature gives advantage in higher jumping reach height and consequent better play match jumping performance of the First league basketball players than in Second league players.

From our results vertical jumping ability of basketball and handball players from Premium league teams is the same in both jumps: counter-movement and free jump (Table 3). Handball players do not need to shot the ball to the basket like basketball players, but taller players with a greater body mass have the ability to achieve a higher ball speed in the jump throw (Wagner et al., 2010).

Power characteristics (including vertical jump height) were better in handball players from higher ranked teams than from lower ranked male elite Greek handball teams (Nikolaidis \& Ingebrigtsen, 2013). The counter-movement jump height in handball players from the best Greek team is $37.7 \pm 3.7 \mathrm{~cm}$ (from our data $47.6 \pm 7.6 \mathrm{~cm}$ ), but free jump height (with movement of the arms) is 46.6 $\pm 4.1 \mathrm{~cm}$ (from our observations $57.1 \pm 10.1 \mathrm{~cm}$ ). The body mass in our and Greek players is the same. Nevertheless Latvian elite handball players vertical jump heights exceed the results of Greek athletes for approximately $10 \mathrm{~cm}$. The countermovement jump height of our players coincides with the data of much heavier Spanish amateur $(46.9 \pm 7.0 \mathrm{~cm})$ and professional players $(46.8 \pm 7.0 \mathrm{~cm})$ (Gorostiaga et al., 2005). From our previous investigation high body mass index observed in qualified handball and football players could be explained with large lean body or muscles mass. We did not determined significant relationship between the body mass index and vertical jumps height in these handball and football players (Pontaga \& Zidens, 2011). Significantly greater power characteristics (counter-movement jump height, handgrip strength, sprint running speed) and aerobic capacity are determined in elite adolescent (14 - 18 year olds) handball players in comparison with the non-elite adolescent athletes (Stijn et al., 2011).

Relative oxygen uptake is greater in our qualified basketball players in comparison with handball players at the anaerobic threshold load intensity and at the maximal intensity load (Table 2). The mean aerobic power of our basketball players $54.2 \pm 5.9 \mathrm{ml} / \mathrm{kg} \cdot \mathrm{min}$ is better than in elite Serbian basketball players indirectly determined relative maximal oxygen uptake: $49.8 \pm 4.9 \mathrm{ml} / \mathrm{kg} \cdot \mathrm{min}$ (52.5 $\pm 4.8 \mathrm{ml} / \mathrm{kg} \cdot \mathrm{min}$ in guards) (Ostojic, 2006) and Lithuanian professional basketball players (in dependence on players position maximal oxygen uptake varied from $46.2 \pm 5.6$ to $52.2 \pm 8.7 \mathrm{ml} / \mathrm{kg} \cdot \mathrm{min}$, but the load test is performed on cycle ergometer, not a customary activity for basketball players) (Gocentas et al., 2011). Aerobic performance is essentially important in basketball players' performance because the distances covered by players during the match play in different phases of the competition varied from 4.02 to $6.17 \mathrm{~km}$ (Borin et al., 
Pontaga \& Zidens, 2018. Comparison of Latvian Qualified Basketball and Handball Players Performance

2013). Anaerobic endurance seems not so important in basketball players because the blood lactate concentration of the athletes at different times of the match and phases of competition did not significantly changed: this concentration varied from $2.24 \pm 0.69$ to $3.37 \pm 0.67 \mathrm{mmol} / \mathrm{l}$ (Borin et al., 2013). Therefore the anaerobic threshold lactate concentration was not reached in the final match play of Brazilian Basketball League competitions. The high mean lactate concentration in periphery blood in our basketball players two minutes after the load test: $9.3 \pm$ $1.3 \mathrm{mmol} / \mathrm{l}$ is not typical during real basketball competitions.

Aerobic endurance is important also in handball players, because a total running distance per match play (from 3.9 to $4.7 \mathrm{~km}$ ) is long, but slightly shorter than in basketball players (Povoas et al., 2012; Michalsik et al., 2013). A mean heart rate during the match is 160 - 170 beats/ min. (Povoas et al., 2012; Wagner et al., 2014), which is close to anaerobic threshold heart rate of our players: 169 \pm 6 beats/ min. The blood lactate concentration after handball match play is $3-11$ $\mathrm{mmol} / \mathrm{l}$ (Wagner et al., 2014), which is higher than in elite basketball players and proves the role of intensive anaerobic glycolysis in energy supply of muscles and therefore more important requirement to anaerobic endurance in handball than basketball players' performance. The relative maximal oxygen uptake in our handball players $(46.5 \pm 4.6 \mathrm{ml} / \mathrm{kg} \cdot \mathrm{min}$.) is low in comparison with the same characteristic in amateur $(57.3 \pm 3.1 \mathrm{ml} / \mathrm{kg} \cdot \mathrm{min}$.$) and professional (58.7 \pm 0.9$ $\mathrm{ml} / \mathrm{kg} \cdot \mathrm{min}$.) athletes from France (Rannou et al., 2001). Wagner et al. (2014) in the review article concluded that handball players in match play need a high aerobic capacity to recover during the low intensity phases to ensure playing on a high level in the high intensity phases: maximal oxygen uptake of 55 - 60 $\mathrm{ml} / \mathrm{kg} \cdot \mathrm{min}$, high level of anaerobic endurance to play at maximal blood lactate concentration of $8-12 \mathrm{mmol} / \mathrm{l}$ during all the game $(2 \times 30 \mathrm{~min})$. Buchheit et al. (2009) measured maximal oxygen uptake and maximal blood lactate concentration in handball players: in the small size game $(60.2 \pm 2.6 \mathrm{ml} / \mathrm{kg} \cdot \mathrm{min}$. and $8.9 \pm 2.3 \mathrm{mmol} / \mathrm{l})$, in the shuttle run $(56.4 \pm 5.2 \mathrm{ml} / \mathrm{kg} \cdot \mathrm{min}$. and $11.6 \pm 1.4$ $\mathrm{mmol} / \mathrm{l})$, and in incremental treadmill running test $(57.3 \pm 4.7 \mathrm{ml} / \mathrm{kg} \cdot \mathrm{min}$. and 9.3 $\pm 1.3 \mathrm{mmol} / \mathrm{l})$. The relative maximal oxygen uptake values in our players are lower by $20-25 \%$ in comparison with these data, but the maximal blood lactate concentration of our handball players determined in incremental treadmill running test $(10.8 \pm 2.0 \mathrm{mmol} / \mathrm{l})$ is greater than from treadmill test performed by Buchheit et al. (2009). This means that our handball players need to improve their aerobic endurance, but the anaerobic endurance of our athletes is comparable with this characteristic in international level handball players. 


\section{Conclusions}

Anthropometric characteristics of high-level our basketball players are close to professional foreign players, but our qualified handball players need to achieve larger mass of skeletal muscles. Power characteristics (counter-movement jump height without and with motions of the arms) in Latvian high-level male basketball and handball players are the same and comparable with vertical jump tests results of international level players of both sport games. Aerobic endurance characteristics of Latvian basketball players coincides with these values in professional international level athletes, but are low and need improvement in our handball players. Anaerobic endurance (determined from maximal lactate concentration in periphery blood two minutes after the treadmill load test performed to exhaustion) is significantly better in Latvian handball than in basketball players, this could be explained by more intensive anaerobic playing activity in handball. The maximal blood lactate concentration in our handball players is similar like in professional athletes from other countries.

\section{References}

Borin, J. P., Daniel, J. F., Bonganha, V., De Moraes, A. M., Cavaglieri, C. R., Mercadante, L. A., Da Silva, M. T. N., \& Montagner, P. C. (2013). The distances covered by basketball referees in a match increase throughout the competition phases, with no change in physiological demand. Open Access Journal of Sports Medicine, 4, 193-198. Doi:10.2147/OAJSM.S42489.

Buchheit, M., Laursen, P. B., Kuhnle, J., Ruch, D., Renaud, C., \& Ahmaidi, S. (2009). Gamebased training in young elite handball players. International Journal of Sports Medicine, 30, 251 - 258. PMID: 19199207.

Dravnieks, J. MS additional program “Statistics 5.01.” Downloaded from [06.01.2018.] http://runcis.lspa.lv/statist.html.

Gocentas, A., Jascaniniene, N., Poprzecki, S., Jaszczanin, J., \& Juozulynas, A. (2011). Positionrelated differences in cardiorespiratory functional capacity of elite basketball players. Journal of Human Kinetics, 30, 145 - 152. Doi:10.2478/v10078-011-0082-1.

Gorostiaga, E. M., Granados, C., Ibanez, J., \& Izquerdo, M. (2005). Differences in physical fitness and throwing velocity among elite and amateur male handball players. International Journal of Sports Medicine, 26, 225 - 232. PMID: 15776339.

Hoffman, J. R. (2003). Physiology of basketball. In: McKeag, D. B. (ed.). Basketball (pp. 1224). Oxford: Blackwell Science.

Ingebrigtsen, J., Rodahl, S., \& Jeffreys, I. (2013). Physical characteristics and abilities of junior elite male and female handball players. Journal of Strength and Conditioning Research, 27, 302-309. Doi:10.1519/JSC.0b013e318254899f.

McInnes, S. E., Carlson, J. S., Jones, C. J., \& McKenna, M. J. (1995). The physiological load imposed on basketball players during competition. Journal of Sport Sciences, 13, 387397. Doi:10.1080/02640419508732254.

Miura, K., Yamamoto, M., Tamaki, H., \& Zushi, K. (2010). Determinants of the abilities to jump higher and shorten the contact time in a running 1-legged vertical jump in 
Pontaga \& Zidens, 2018. Comparison of Latvian Qualified Basketball and Handball Players Performance

basketball. Journal of Strength and Conditioning Research, 24, 201-206. Doi:10.1519/JSC.0b013e3181bd4c3e.

Michalsik, L. B., Aagaard, P., \& Madsen, K. (2013). Locomotion characteristics and matchinduced impairments in physical performance in male elite team handball players. International Journal of Sports Medicine, 34, 590-599. Doi:10.1055/s-0032-1329989.

Nikolaidis, P. T., \& Ingebrigtsen, J. (2013). Physical and physiological characteristics of elite male handball players from teams with a different ranking. Journal of Human Kinetics, 38, 115-124. Doi:10.2478/hukin-2013-0051.

Ostojic, S. M., Mazic, S., \& Dikic, N. (2006). Profiling in basketball: physical and physiological characteristics of elite players Journal of Strength and Conditioning Research, 20, 740 4. Doi:10.1519/R-15944.1.

Pehar, M., Sekulic, D., Sisic, N., Spasic, M., Uljevic, O., Krolo, A., Milanovic, Z., \& Sattler, T. (2017). Evaluation of different jumping tests in defining position-specific and performance-level differences in high level basketball players. Biology of Sport, 34, 263272. Doi:10.5114/biolsport.2017.67122.

Pontaga, I., \& Zidens, J. (2011). Estimation of body mass index in team sports athletes. LASE Journal of Sport Science, 2 (2), 33 - 44.

Pontaga, I., \& Zidens, J. (2012). Comparison of anthropometric and performance characteristics in amateur and professional level handball players. LASE Journal of Sport Science, 3 (1), 47- 54.

Povoas, S. C. A., Seabra, A. F. T., Ascensao, A., Magalhaes, J., Soares, J. M. C., \& Rebelo, A. N. C. (2012). Physical and physiological demands of elite team handball. Journal of Strength and Conditioning Research, 26, 3365-3375. Doi:10.1519/JSC.0b013e318 248aeee.

Rannou, F., Prioux, J., Zouhal, H., Gratas - Delamarche, A., \& Delamarche, P. (2001). Physiological profile of handball players. Journal of Sports Medicine and Physical Fitness, 41, 349 - 353. PMID: 11533566.

Sjodin, B., \& Jacobs, I. (1981). Onset of blood lactate accumulation and marathon running performance. International Journal of Sports Medicine, 2, 23 - 26. Doi:10.1055/s-20081034579.

Stijn, P. J. M., Vaeyens, R., Vandendriessche, J., Vandorpe, B., Pion, J., Aaron, J., Coutts, A. J., Lenoir, M., \& Philippaerts, R. M. (2011). A multidisciplinary identification model for youth handball. European Journal of Sport Science, 11, 355 - 363. http://dx.doi.org/ 10.1080/ 17461391.2010.523850.

Struzik, A., Pietraszewski, B., \& Zawadzki, J. (2014). Biomechanical analysis of the jump shot in basketball. Journal of Human Kinetics, 42, 73-9. Doi:10.2478/hukin-2014-0062.

Wagner, H., Buchecker, M., von Duvillard, S. P., \& Müller, E. (2010). Kinematic description of elite vs. low level players in team handball jump throw. Journal of Sports Science and Medicine, 9, 15-23. PMCID: PMC3737958.

Wagner, H., Finkenzeller, T., Würth, S., \& von Duvillard, S. P. (2014). Individual and Team Performance in Team-Handball: A Review. Journal of Sports Science and Medicine, 13, 808-816. PMCID: PMC4234950.

Zapartidis, I., Gouvali, M., Bayios, I., \& Boudolos, K. (2007). Throwing effectiveness and rotational strength of the shoulder in team handball. Journal of Sports Medicine and Physical Fitness, 47, 169 - 178. PMID: 17557054. 
Zapartidis, I., Vareltzis, I., Gouvali, M., \& Kororos, P. (2009). Physical fitness and anthropometric characteristics in different levels of young team handball players. The Open Sports Sciences Journal, 2, 22 - 28. Doi:10.2174/1875399X00902010022.

Ziv, G., \& Lidor, R. (2009). Physical characteristics, physiological attributes, and on-court performances of handball players: A review. European Journal of Sport Science, 9, 375-386. Doi:10.1080/17461390903038470. 